
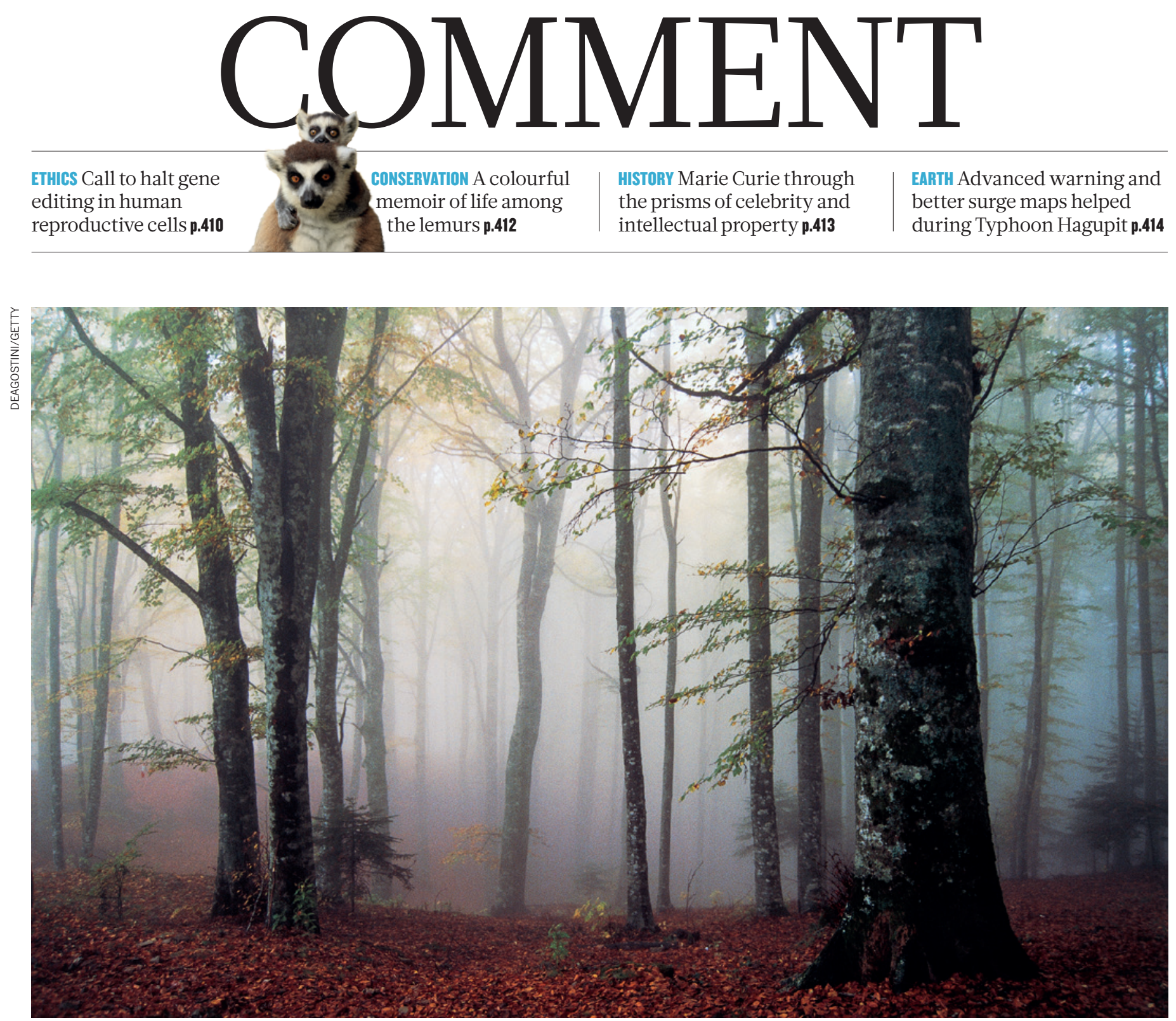

Beech trees, which are vulnerable in warm, dry conditions, are more protected in mixed forest stands.

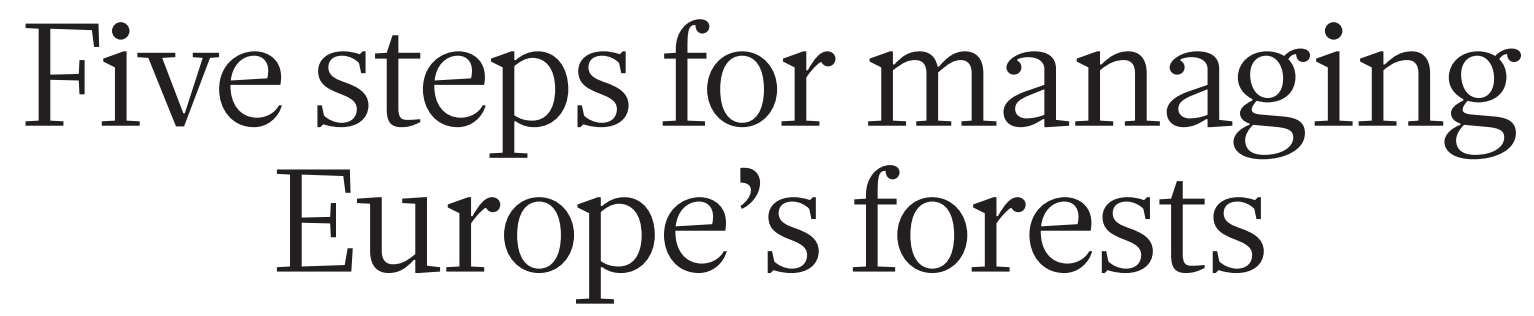

Support resilience and promote carbon storage, say Silvano Fares and colleagues.

$\mathrm{E}$

urope's varied climates support some of the most biodiverse woodlands on Earth. More than $40 \%$ of the continent's land area is wooded. In the north, evergreen forests host Norway spruces and Scandinavian pines; around the Mediterranean, tough-leaved trees such as the holm oak and Aleppo pine withstand heat and drought. Dense beech and oak forests blanket Eastern Europe, and thin strands of dwarf pine mark the Alpine timberline.
Woodlands in Europe have been harvested for timber for thousands of years, but today their roles are multiplying. Wood can substitute for fossil fuels and carbonintensive materials such as steel. And growing trees sequester carbon - photosynthesis absorbs carbon dioxide from the atmosphere and puts it in wood and soil. Forests remove around $9 \%$ of Europe's anthropogenic $\mathrm{CO}_{2}$ emissions from the air ${ }^{1}$.

But European forests face an uncertain future. More frequent heat waves, droughts and fires are reducing their health and productivity, with the region warming faster than the global average ${ }^{2}$. Urban sprawl, pollution and the expansion of transport, commercial and industrial infrastructure compound the climatic threats ${ }^{3}$.

Such damage is offsetting gains from planting programmes and the natural reforestation of abandoned agricultural land, which have boosted Europe's woodland 
area by $9 \%$ since 1990 . Disturbances also outpace the extra plant growth that arises under higher concentrations of atmospheric $\mathrm{CO}_{2}$. Since 2005, the amount of wood produced annually across Europe has decreased by around $0.3 \%$ a year (in 2010, it was 620 million cubic metres over 157 million hectares in 27 countries) ${ }^{1}$.

The resulting picture has two sides: new forests are gaining ground and pushing up overall forest area, but existing stands are becoming less productive with age and damage.

We outline five key issues that European forestry managers should address to develop Europe's forests sustainably and with resilience in mind ${ }^{4}$. Policies and plans must account for the trade-offs between forests' capacity to store carbon, adapt to climate change and yield wood products and other ecosystem services.

Forest carbon sequestration needs to be incorporated into European Union (EU) mitigation schemes, including the EU Emissions Trading System, which currently considers only forest planting and regeneration. Incentives will be needed to double carbon-neutral biomass production by 2020 to meet Europe's renewable-energy needs. Payment schemes should be set up for a range of woodland services such as water storage and recreation. Many of these lessons apply to forest management in other parts of the world, including the United States and China.

\section{KEY ISSUES}

Plant resilient species. Woodland regeneration offers foresters a chance to manipulate the mix of species and quality of plants to better withstand long-term environmental changes. Managers should plant species that tolerate a variety of climates, such as those that can grow over a range of latitudes and altitudes. Mixed stands are more resistant to pests and disturbances than those of single species, which succumb easily to such threats. They also shelter sensitive species such as beech that become vulnerable in warm, dry conditions. Germany, for example, is including beech and oak in its spruce and pine forests.

Plant breeders in nurseries and laboratories should increase the genetic diversity of stock and take steps to assure plant quality. They should foster traits such as the ability to adapt to higher $\mathrm{CO}_{2}$ concentrations, warmer temperatures or longer periods of water stress. Programmes for conserving genetic resources, such as those established for Mediterranean pines, the European chestnut and several oak and poplar species, should be strengthened.

Guidelines for plant production in nurseries need updating. These are usually generic - designed for a stable climate rather than local or varying conditions. The
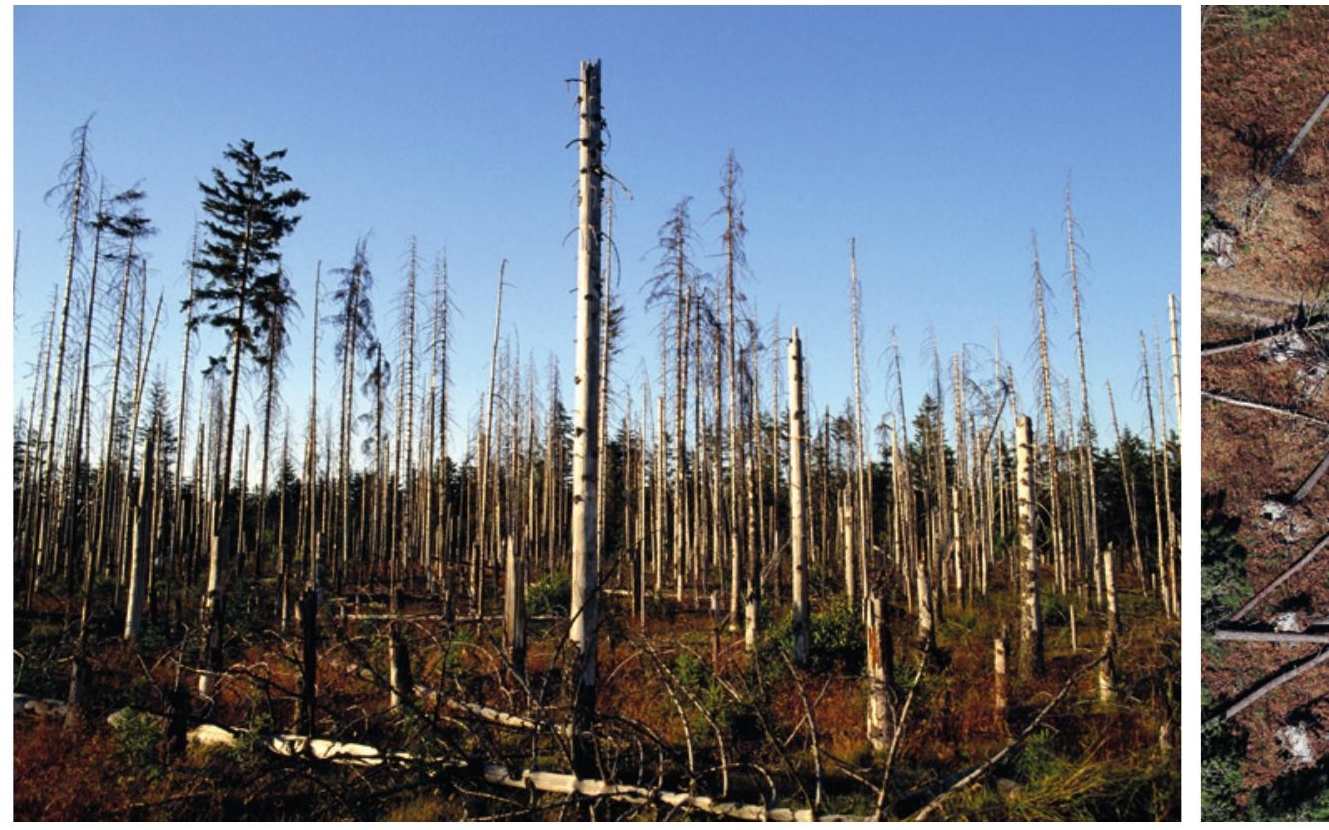

Trees damaged by acid rain in the polluted 'black triangle' of the northern Czech Republic.

selection of genetic material and nursery practices should aim to increase the survival rate of stock. For instance, to lower the water stress of seedlings, moisture-preserving chemicals should be used more widely in seedling production, transport and planting.

Managers should use locally gathered seeds and natural regeneration methods as promoted by the European Forests Genetic Resources Programme (EUFORGEN) where possible to preserve the existing diversity of species. Several nations, including the United Kingdom and France, have defined areas where only

local variants of trees should be planted.

Best practice should involve: first, testing the provenance of seeds and assessing the genetic variation among populations; and second, analysis of climate trends to decide when it makes sense to transfer species from south to north ${ }^{5}$. Silver-fir seeds from southern Europe are increasingly being planted farther north, for example.

Promote carbon storage. Foresters should craft tending and thinning strategies for woodlands to promote the most resilient species. In the far north and at high altitudes, where growth rates will rise most under warmer and $\mathrm{CO}_{2}$ - and nitrogen-rich conditions, managers should thin saplings more often or harvest more established trees each year.

The timing of harvests needs to be optimized. Commercial pressures dictate frequent harvests and thus short rotations (the time between timber establishment and harvest). But longer rotation cycles are needed to promote carbon storage. The win-win strategy ${ }^{6}$ lies in between. Adopt long cycles in old, healthy forests that are at low risk from pests or environmental disturbances, such as mountain beech stands. Forests such as pine plantations that are prone to wildfires and other major disturbances should be harvested more intensely.

Mature forests - where growth has stalled - can turn quickly from carbon sinks to sources when damaged by storms and pests. Breakdown of dead wood by microorganisms in the soil releases carbon. Many of Europe's stands are mature or decaying. Only $4 \%$ are 'primary' forests - those undisturbed by humans - which sustain their high biodiversity and carbonstorage capacity ${ }^{1}$. Thinning can encourage new growth and increase structural diversity. Increasing canopy complexity by selecting trees with different heights promotes more efficient use of light and nitrogen ${ }^{7}$ and boosts carbon sequestration.

European and wood-market policies should manage this shift over the next few years. For example, greater uptake of tax benefits by forest owners in the European Commission's Common Agricultural Policy would support more adaptation measures.

Manage disturbances. More pests, winds and wildfires offset strategies aiming to increase forest carbon storage. Foresters need plans to cut pests and improve forest health and stability.

In pure stands, the selection of resistant families and clones could reduce the risk of damage by pests and diseases. Scientists need to understand why different diseases and pests become problematic by studying 

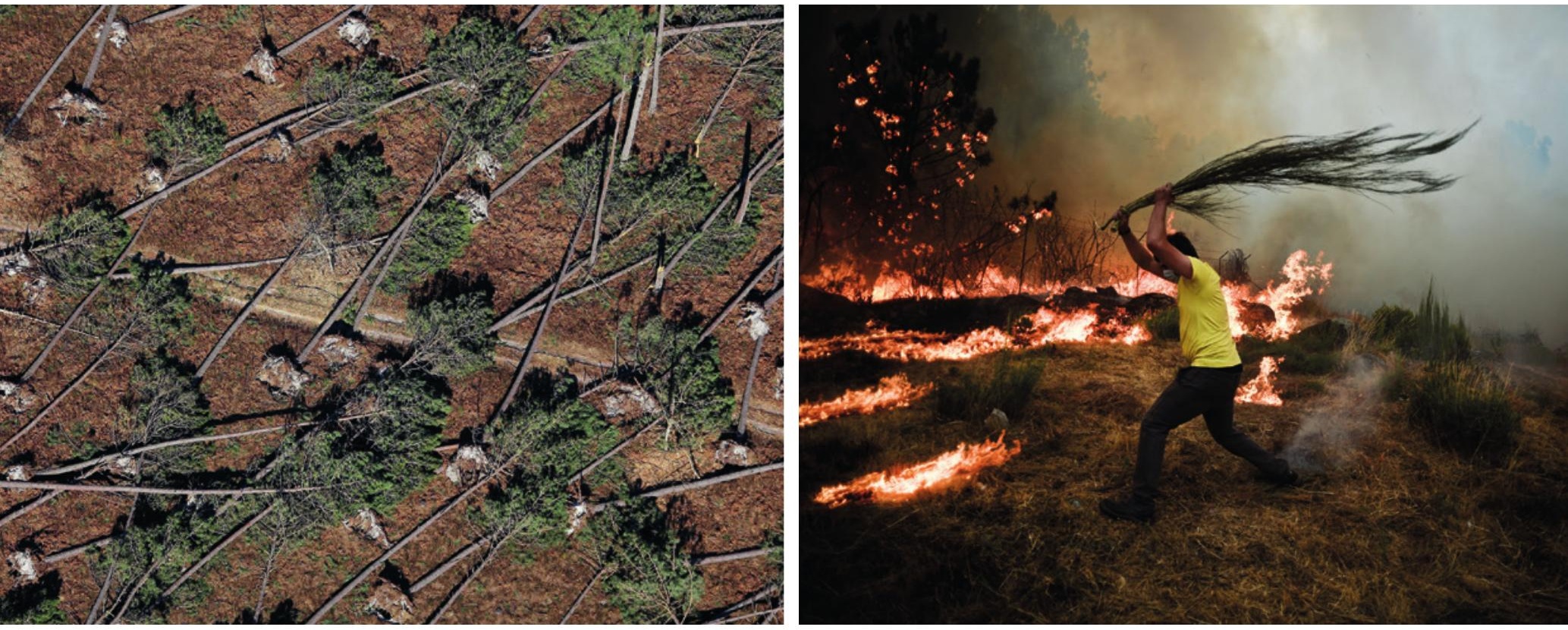

Damaged forests (left) can turn from carbon sinks to sources. Forest fires (right) can be mitigated by removing biomass material.

specific forest communities affected by particular pathogens or insects. Foresters are using such studies to combat, for example, infestations of the Eurasian spruce bark beetle in Slovenia and Poland and chestnut ink disease in the United States and Italy.

For fire prevention, policy-makers should incentivize practices that reduce the accumulation of fuel: prescribed burning, thinning, pruning and biomass removals, grazing and the creation of a mosaic of forest types including less-flammable species. Such approaches are cheaper than conventional air and ground-based fire-fighting, which may even raise fire risk by leaving biomass to proliferate. Mega-fires covering hundreds of hectares are increasingly common ${ }^{8}$.

Consider renewable energy. Forest biomass currently accounts for $60-80 \%$ of the EU's total renewable-energy consumption. By 2020 , the EU aims to provide $20 \%$ of its energy from renewable sources. This would require doubling the use of biomass, the equivalent of all of today's harvest going to energy. Currently, only two-thirds of annual growth is harvested and only about $40 \%$ of that is used for bioenergy.

Global changes in the production, consumption and trade of forest commodities make it hard for Europe to mobilize forest biomass through markets alone. Policymakers need to provide incentives for investment across the supply chain, and the impacts of such policies should be considered carefully. For example, subsidizing biodiesel production would increase the price of forest biomass and thus lessen its use in generating heat and power. To ensure that bioenergy production is environmentally and economically sustainable, reseachers should analyse the carbon balance of the biomass-production process, the impacts on biodiversity, trade-offs with alternative forest uses, and the socio-economic viability of biomass production?

Quantify and market other benefits. Non-wood products and services from forests - related to conservation, water and soil protection, recreation or climate-change mitigation and adaptation - are now excluded from the market. Introducing payments for them would encourage private landowners to manage their forests sustainably ${ }^{10}$ (about half of European forests are in private hands). A water company, for example, might pay foresters to protect a catchment; citizens might pay to enter a woodland for recreation.

The EU Forest Strategy recognizes the importance of valuing ecosystem services in accounting systems at EU and national levels by 2020 . The challenge is to quantify the value of particular services based on the perceived benefits ${ }^{10}$. Governments and forest owners need to develop strategies for making environmental service payments: small amounts might be negotiated directly between buyers and sellers; large amounts might involve government agencies or other intermediaries.

Billions of euros are earmarked for forestry for 2014-20 in the EU 2020 Biodiversity Strategy and EU rural development fund. Europe's forestry community needs to implement a sustainable management strategy to secure its woodlands, and their ecosystem services, for future generations.

Silvano Fares is a research scientist at the Research Centre for the Soil-Plant System, Council for Agricultural Research and Economics, Rome, Italy. Giuseppe Scarascia Mugnozza is director of the Department for Innovation in Biological, Agro-food and Forest Systems at Tuscia University, Viterbo, Italy. Piermaria Corona is director of the Forestry Research Centre, Council for Agricultural Research and Economics, Arezzo, Italy. Marc Palahí is director of the European Forest Institute, Joensuu, Finland.

e-mail:silvano.fares@entecra.it

1. Forest Europe, UNECE and FAO. State of Europe's Forests 2011 (Ministerial Conference on the Protection of Forests in Europe, 2011).

2. IPCC. Climate Change 2013: The Physical Science Basis. Contribution of Working Group I to the Fifth Assessment Report of the Intergovernmental Panel on Climate Change (IPCC, 2013).

3. Nabuurs, G.-J. et al. Nature Clim. Change $\mathbf{3}$, 792-796 (2013).

4. Lindner, M. et al. Forest Ecol. Mgmt 259, 698-709 (2010).

5. Kolström, M. et al. Forests 2, 961-982 (2011).

6. Bellassen, V. \& Luyssaert, S. Nature $\mathbf{5 0 6}$, 153-155 (2014).

7. Hardiman, B. S. et al. Forest Ecol. Mgmt 298, 111-119 (2013).

8. Birot, Y. (ed.) Living with Wildfires: What Science Can Tell Us (European Forest Institute, 2009).

9. Hetemäki, L., Muys, B., Pelkonen, P. \& Pettenella, D. ThinkForest: Forest Bioenergy for Europe (eds Pelkonen, P. et al.) (European Forest Institute, 2014).

10.Prokofieva, I., Wunder, S. \& Vidale, E. Payments for Environmental Services: A Way Forward for Mediterranean Forests? (European Forest Institute, 2012).

\section{CORRECTION}

In the Comment 'Put people at the centre of global risk management' (Nature 519, 151-153; 2015), the credit for the lead picture should have read Abbie TraylerSmith/Panos Pictures. 